\title{
Entrevista com Benjamin Abdala Jr. Interview with Benjamin Abdala Jr.
}

\section{Luís Fernando Prado Telles'}

entrevista que segue foi concedida pelo professor Dr. Benjamin Abdala Jr. ${ }^{2}$, em 07 de fevereiro de 2014, nas dependências do Centro de Estudos das Literaturas e Culturas de Língua Portuguesa, sediado na Universidade de São Paulo. Tal entrevista foi realizada como atividade integrante de uma pesquisa por mim desenvolvida em nível de Pós-Doutorado que procurava investigar a memória da área de Literatura Portuguesa nas Universidades Brasileiras ${ }^{3}$. No depoimento que segue, o professor Benjamin Abdala Jr. fala de sua experiência como aluno

1 Professor Adjunto de Teoria Literária da Escola de Filosofia, Letras e Ciências Humanas da Universidade Federal de São Paulo - EFLCH/UNIFESP.

2 Professor da Área de Estudos Comparados de Literaturas de Língua Portuguesa, do Departamento de Letras Clássicas e Vernáculas (DLCV) da Faculdade de Filosofia Letras e Ciências Humanas (FFLCH) da Universidade de São Paulo (USP).

3 O projeto intitulou-se, inicialmente, A presença da Literatura Portuguesa no Brasil: percursos e percalços do ensino e da pesquisa no processo de constituição da área de Literatura Portuguesa nas universidades brasileiras. A pesquisa teve como sede o Departamento de Letras Clássicas e Vernáculas da FFCLH/USP e foi financiada pela FAPESP (Processo 2013/07623-3). No período de tempo compreendido pelo relatório apresentado ao órgão de fomento do projeto, a pesquisa completou a investigação nas universidades públicas do Estado de São Paulo: USP; UNICAMP, UNESP (Assis; Araraquara e São José do Rio Preto); UFScar e Unifesp. Em cada uma destas universidades, a pesquisa pautou-se por quatro frentes de investigação: 1. Memória institucional (sobre o curso de Letras e sobre a área de Literatura Portuguesa); 2. Documentação acadêmica (de Graduação e Pós-Graduação); 3. Pesquisa (levantamento da produção na área de Literatura Portuguesa, em termos qualitativos e quantitativos); 4. Depoimentos (por meio de entrevistas orais ou escritas). 
do curso de Letras da USP, de como foi atraído ao estudo da Literatura Portuguesa e de que maneira a perspectiva comparatista esteve já presente desde o início de suas pesquisas em literatura. Discorre ainda sobre as implicações políticas e ideológicas que o levaram a assumir tal perspectiva frente ao estudo e ao ensino da literatura, postura esta que tem a ver com sua história de vida e com seu percurso intelectual, marcado pela constante luta pela integração comunitária das diferentes culturas dos povos falantes da língua portuguesa. A entrevista foi gravada e posteriormente transcrita, o que resultou no tom coloquial do texto que aqui procurei conservar.

Luís Fernando Prado Telles: Observando o início de sua trajetória intelectual, é possível perceber que da passagem de seu mestrado para o doutorado há já uma inflexão que indica uma preocupação com os estudos comparados. No mestrado, o senhor focou no estudo da obra do escritor português Carlos de Oliveira, já no doutorado, a relação entre os romances deste e os de Graciliano Ramos. De certo modo, é possível ver nesse início o gérmen da criação da área de Estudos Comparados. Contudo, seus estudos de pós-graduação tiveram início no domínio da área de Literatura Portuguesa, justamente no ano de 1971, quando se constituíram de modo institucionalizado os Programas Específicos de Pós-Graduação na FFLCH. Como a presente pesquisa tem o foco no estudo da presença da Literatura Portuguesa nas Universidades Brasileiras, gostaria de saber como o senhor foi atraído, inicialmente, ao estudo da Literatura Portuguesa e como foi sua formação nessa área?

Benjamin Abdala Jr.: Bem, a respeito de minha trajetória. Eu entrei na pós-graduação em 1971. Eu havia sido preso político, fiquei preso por um ano e meio, entre 1969 e 1971, e justamente quando eu estava ainda preso, a professora Maria Aparecida Santilli, que tinha sido minha professora de graduação (eu fiz um curso sobre o neorrealismo português com ela) soube que eu ia sair da cadeia e, então, sugeriu que eu fizesse a pós-graduação com ela. Assim, eu entrei na pós e no ano seguinte, em 1972, fui pesquisar em Portugal. Tinha uma bolsa de um ano, mas acabei ficando por apenas dez meses, por razões pessoais. E lá, então, quem me supervisionou em minha pesquisa em Portugal foi o professor Jacinto do Prado Coelho, da Universidade de Lisboa. Lá desenvolvi minha pesquisa sobre o neorrealismo português, mais especificamente sobre a obra de 
Carlos de Oliveira. Em Portugal, eu fui muito bem recebido em Lisboa pelo Carlos de Oliveira que me apresentou o grupo em torno dele, entre aspas, neorrealistas, porque o próprio Carlos de Oliveira nunca aceitou essa designação. E era um grupo muito curioso, porque eles se reuniam todos os dias, às 5 horas da tarde, no café Monte Carlo. Nesse grupo, participava o próprio Carlos de Oliveira, que era a figura central, mas estava sempre também lá o Augusto Abelaira, o José Gomes Ferreira e o Herberto Helder. Veja bem que o conceito de neorrealismo aí fica um pouco complicado, não é mesmo? Na verdade, eram todos antissalazaristas. E havia outros que também passavam por lá, tal como o José Cardoso Pires, inclusive eu o conheci por lá e também tive muito contato com outros escritores que não frequentavam muito o café, tal como o Fernando Namora. Estive bastante próximo também do Manuel da Fonseca e do pessoal da música, como o Adriano Correia de Oliveira. Era o pessoal de uma militância antissalazarista. Lembro-me que o Manuel da Fonseca tinha feito um long play em que o Adriano Correia de Oliveira, que era um dos cantores mais populares de Portugal da época, musicou os seus poemas. Na época, o Adriano convidou o Manuel e eu para um jantar, em que ele mesmo preparou a comida. Realmente, um jantar maravilhoso, em que estiveram presentes militantes contra a ditadura. Ao final do jantar, ele resolveu me presentear com um long play, e eu o peguei em minhas mãos e disse-Ihe: "Assim não vale, você precisa colocar um autógrafo. Ele olhou para mim e me disse: "que é isso! Que costume mais burguês!". Eu não sabia onde enfiar a cara. Enfim, isso é mais folclórico...

Foi um pessoal que me recebeu muito bem em Portugal. O Carlos de Oliveira sabia do meu passado político, eu havia sido, antes, secretário geral do Grêmio da então Faculdade de Filosofia, Ciências e Letras da Universidade de São Paulo. Fui diretor do jornal do Grêmio, chamado "Amanhã", um jornal que tinha tiragem de dez mil exemplares. Era vendido nas bancas e nós íamos partir para a distribuição nas principais capitais do país, com uma tiragem de 30 mil exemplares. Mas aí a polícia deu em cima, isso foi em 67 e eu estava no segundo ano da graduação do curso de Letras. Depois da investida da polícia, acabamos por fechar o jornal. Era um jornal que teve repercussão na época. Tinha charges do Fortuna, do Jaguar e até contribuição do (Otto Maria) Carpeaux. Um jornal ponte entre os estudantes e a sociedade, para vender nas bancas. E o Grêmio da USP daquela época era uma potência, inclusive em termos econômicos. Possuía o melhor cursinho de humanas em São Paulo e os professores eram alunos da 
USP. Havia mesmo alunos que retardavam a formatura para poderem continuar a dar aulas no cursinho do Grêmio, porque pagava bem. E mesmo alunos com dificuldades políticas e que lá ficavam. Enfim, era de lá que vinha o dinheiro, e com isso mantínhamos o jornal e, inclusive, mantivemos uma revista, chamada "Revisão". Essa revista foi fechada pela polícia. Foi fechada, inclusive, com prisão dos editores, por conta de uma entrevista com o Caio Prado [Júnior]. Os entrevistadores, como o nosso grande intelectual, chegaram a pegar um ano e meio de cadeia. Haviam sido condenados há quatro anos... Isso foi por volta de 1968, um pouco antes de eu ser preso. Eu fui preso primeiro pelo Deops de São Paulo e levado para o Deops de Santos, de onde acabei por ser encaminhado para o exército no Forte Itaipu, em Santos. Solto, depois eu fui preso pela Operação Bandeirantes, fiquei 15 dias sob tortura (cadeira do dragão) na $O B$, que foi o que antecedeu o DOI-Codi, e depois fui para o Deops de São Paulo e, na sequência, para o Presídio Tiradentes.

Luís Fernando Prado Telles: E nesse tempo o senhor ficou longe de qualquer contato com o estudo ou era possível fazer leituras, era possível ter algum tipo de vida intelectual ou não?

Benjamin Abdala Jr.: Na Operação Bandeirantes, era impossível, porque foram 15 dias de tortura. Ocorreu comigo e acontecia com qualquer pessoa que passasse por lá. No Deops também não tinha possibilidade. Agora, no Presídio Tiradentes, já ia pra lá quem estava com o processo formalizado. Inclusive, na OB, só para você ter uma ideia, os torturadores disseram para mim assim: "Você não existe". Eu entendi aquilo como uma ameaça, porque a OB não existia do ponto de vista legal. Era uma organização interna envolvendo o Exército, a Aeronáutica e a Marinha, juntamente com o Deops. Depois resolveram legalizar isso, mais ou menos em 1970. Legalização entre aspas, isto é, legalização da tortura; ou meIhor, sua institucionalização com o nome de DOI-Codi. Existia o apoio de alguns capitalistas, o apoio da Folha de S. Paulo, por exemplo, e de alguns industriais, da época, que financiavam. Inclusive, presenteavam os torturadores com dinheiro em função das prisões que faziam ou das pessoas que matavam. Enfim, uma coisa muito séria... Mas essa é uma outra história... Mas então, eu fui para Portugal e fui bem recebido pelo Carlos de Oliveira, que todo mundo falava que era uma pessoa muito difícil. 
Luís Fernando Prado Telles: E, nessa época, Portugal passava por um período político difícil também, pois estavam sob o regime da ditadura, não? Benjamin Abdala Jr.: É. Na época, o Salazar já havia morrido, mas o regime era o mesmo, com Marcelo Caetano, que assumiu o poder no lugar dele. Na épo$\mathrm{ca}$, inclusive, houve um aguçamento da guerra colonial. Em contrapartida, havia muitas manifestações na universidade contra a guerra colonial. Era terrivelmente muito curioso, porque algum aluno se colocava a discursar, a protestar, de repente essa pessoa sumia. Fazia um discurso e sumia, enfim, a situação era bastante difícil.

Enfim, essa vivência toda vai ter uma consequência em minha vida profissional, inclusive depois de meu ingresso na USP, em 1977. A partir desse contato com os escritores portugueses, ficou muito clara para mim a necessidade de se pensar, comunitariamente, Brasil e Portugal. Uma estratégia política, pensar os países de língua portuguesa, apesar de que na época não se falava de África, ainda. Em princípio, pensávamos Brasil e Portugal. Em primeiro lugar, eu já havia começado a fazer pós-graduação na área de Literatura Portuguesa, mas o meu projeto era comparativo, já no projeto de Mestrado: uma comparação entre Carlos de Oliveira e Graciliano Ramos.

Quando voltei de Portugal, então, estava com bolsa da Fapesp e comecei a lecionar na USP. Não apenas eu, mas uma série de outros professores, tais como a professora Nadia Battella Gotlib, ela estava vinculada à Literatura Portuguesa; a Maria Lúcia Dal Farra, que trabalhava com a obra de Virgílio Ferreira. Aliás, eu conheci o Virgílio Ferreira por meio da Maria Lúcia, com a qual eu me encontrei em Portugal. Em princípio, o Virgílio me pareceu um sujeito um pouco maçante, porque se mostrava uma pessoa muito voltada para si própria. Era todo voltado para ele e sua obra literária. Só falava de si próprio (não à toa que a Maria Lúcia acabou escrevendo um livro que levava no título a seguinte expressão "o narrador ensimesmado"). Aí está a principal diferença entre este escritor e o Carlos de Oliveira, pois o Carlos nunca falava dele. Eu, algumas vezes, o provocava, por exemplo, quando eu ia para sua casa, em algum jantar, entre um vinho e outro. Tentava, então, entrar em alguma questão mais pessoal, ele me respondia que o que podia afirmar estava em seu livro "O aprendiz de feiticeiro". Nesses jantares, tínhamos mais conversas sobre política, coisas culturais, inclusive quando 
se citavam outros autores, ele se furtava a tecer comentários negativos. Era um sujeito muito ético.

Então, formou-se um grupo de professores em torno da área de Literatura Portuguesa, mas muitos acabaram se desgarrando um pouco da área, pelas dificuldades internas. A Nádia, a Maria Lúcia, a Nelly Novaes Coelho; estas professoras, por exemplo, tomaram outros rumos. A Nádia saiu da literatura Portuguesa e foi para a Brasileira, a Maria Lucia não ficou na USP, foi para a Unicamp e a Nelly acabou focando mais no campo das literaturas infantil e feminina, a partir de um certo momento mais difícil.

Eu entrei na USP apenas em 1977. Fiquei mais de um ano nas malhas da triagem ideológica da Reitoria. Só fui admitido após a formação de uma comissão de investigação da Assembleia Legislativa. Começava o processo de redemocratização do país e o papel da professora Maria Aparecida Santilli foi fundamental nesse sentido.

Luís Fernando Prado Telles: A professora Santilli foi a pessoa fundamental na sua formação e para atraí-lo para a Literatura Portuguesa, não?

Benjamin Abdala Jr.: Sim, ela foi a grande responsável por minha formação, e eu fui atraído para a Literatura Portuguesa por causa de sua disciplina sobre o neorrealismo português. Porque o neorrealismo? Porque como nós estávamos sob a ditadura, e eram escritores que colocavam as questões todas políticas e, é claro, ao discutir os livros deles, era um jeito de falar indiretamente das questões políticas do Brasil. Foi por isso que me atraiu, eu tinha uma militância política muito forte, a minha pesquisa sempre foi pautada pelas relações entre literatura e política. E quando eu entrei na USP, além de dar aulas de Literatura Portuguesa, eu auxiliava a Maria Aparecida Santilli com as aulas sobre Literaturas Africanas. Nossa disciplina foi pioneira na criação da área de estudos de Literaturas Africanas de Língua Portuguesa no Brasil.

Com isso, também, eu comecei a desenvolver todo um sentido novo para o Ensino de Literatura Portuguesa. Eu fui convidado, isso foi em 1979 ou 1980, para um evento organizado pela Lélia Parreira Duarte que ocorreu em Minas Gerais. A Lélia era a pessoa da Literatura Portuguesa da UFMG. E na seção plenária, que era sobre ensino de literatura portuguesa, então, eu me vi acompanhado pelo professor Celso Cunha, pelo professor português que lecionava em Assis, o Fernando Mendonça, e o professor Luís Piva, de Brasília. Era uma das sessões 
iniciais do Encontro Brasileiro de Professores de Literatura Portuguesa e essa mesa era coordenada pelo professor Massaud Moisés. ${ }^{4}$ Nessa comunicação, em que fui o último a falar, a perspectiva que eu defendi foi a de que a Literatura Portuguesa deveria ser ensinada para os brasileiros numa perspectiva brasileira e contemporânea. Em termos de ensino, nós deveríamos romper com o ensino historicista e tentar ganhar o aluno para Literatura Portuguesa, colocando já desde a graduação os principais autores do nosso tempo. Porque, naquela época, nos cursos da Literatura Portuguesa, a literatura contemporânea era relegada para segundo plano. Mesmo o Fernando Pessoa aparecia de modo esporádico. Prevalecia a literatura inicial até o classicismo e tal... E, mais, colocava-se no programa autores secundários apenas para se obedecer à ordem historicista. Então, a minha ideia era ganhar o aluno para a Literatura Portuguesa apresentando a ele, num primeiro momento, os principais autores e de uma perspectiva em que mostrasse para o aluno que a literatura portuguesa tem muito a mostrar para a sua realidade e também para a realidade brasileira. Defendia a perspectiva brasileira de estudo da literatura portuguesa, quer dizer, inclusive, porque essa perspectiva, quer você queira ou não, entrará, pois é o lugar de onde você fala, ou valendo-nos da linguagem da internet, de onde acessamos o mundo. É o nosso lócus enunciativo. Aliás, o modo dominante de como era realizado então o estudo da Literatura Portuguesa, à época, era à maneira antiga. Portugal, como referência, por exemplo, não era o país contemporâneo, era um Portugal antigo, era o Portugal "meu avozinho", bem folclórico, do campo, ou seja, bem ao gosto do salazarismo.

Aí, justamente, eu defendia o estudo dos grandes autores contemporâneos, quer dizer, propunha centralizar os cursos primeiro nesses autores no sentido de mostrar que a realidade deles também poderia ser vista como nossa.

\footnotetext{
4 O evento referido, aqui, pelo professor Benjamim Abdala Jr. pertencia ao VII Encontro Nacional de Professores Universitários de Literatura Portuguesa, ocorrido na Universidade Federal de Minas Gerais, em Belo Horizonte, no período de 01/08/1979 a 05/08/1979. A mesa redonda referida aqui se intitulava "Técnicas atuais de estudo de Literatura Portuguesa em nível universitário no Brasil". Essa mesa redonda ocorreu no segundo dia do evento, cujo tema maior era "O estudo da Literatura Portuguesa em nível universitário no Brasil". Cf. Anais do VII Encontro Nacional de Professores Universitários de Literatura Portuguesa. Belo Horizonte-MG: UFMG, 1979. p. 16. A comunicação do professor Benjamim Abdala Jr. encontra-se publicada na página 83 deste anuário, sob o mesmo título que leva a mesa redonda.
} 
Então aconteceu o seguinte naquela mesa redonda: depois que eu terminei de falar e antes mesmo que passássemos a palavra ao público para perguntas, o professor (Fernando) Mendonça resolveu me interpelar. Ele começou até concordando comigo, dizendo que ele até achava que o estudo dos autores contemporâneos era importante e tal, mas que esse negócio de relacionar a Literatura Portuguesa com a brasileira resultava num certo demérito para a Literatura Portuguesa. Na época, eu ainda era meio esquentado (risos...), já ia responder meio que irritado, até as professoras Maria Aparecida Santilli, a Nádia Battella Gotlib e a Elza Miné fizeram sinais para mim, para que eu me mantivesse calmo. Bem, mas antes que eu respondesse, uma senhora que eu não sabia quem era e que estava na plateia pediu a palavra e defendeu tudo aquilo que eu disse, mas que tinha uma observação a fazer, que a relação entre as literaturas não se limitasse apenas ao Brasil, mas que se estendesse à França e outros países. Bem, eu não sabia quem era essa senhora, mas depois eu vim a saber que era a professora Dirce Côrtes Riedel. E, na sequência, ela começou a criticar a própria perspectiva que se tinha dado ao tema em debate, porque esse congresso foi muito bem organizado e em razão disso os textos das comunicações foram distribuídos com um mês de antecedência, de modo que isso propiciava o debate no momento do encontro. $O$ evento tinha sido organizado pela Lélia (Parreira Duarte).

Bem, essa perspectiva a partir do comparatismo em minha carreira já vinha desde o final da graduação. Eu pensava em todo um repertório literário ligado à língua portuguesa e como esse repertório é apropriado pelas culturas. Quando chegaram as literaturas africanas, foi depois do 25 de abril que comecei a tomar consciência delas, passei a pensar nesse macrossistema linguístico e literário e a desenvolver minhas pesquisas. Um dos tópicos que comecei a desenvolver bastante, até simbolicamente, foi baseado no fato de que os africanos viam, sob a perspectiva do colonialismo, Portugal como pátria, mas a África como mátria. Defendiam a mátria, a terra, aquela mãe África que fora profanada pela figura paterna, masculina e tal. E, no caso dos africanos de língua oficial portuguesa, eles olhavam para o Brasil como uma frátria. Agora, isso aconteceu inclusive porque havia vinculação da Literatura Brasileira entre os africanos, mas sobretudo a partir de Lisboa, através da Casa dos Estudantes do Império. Nessa casa, lia-se muita Literatura Brasileira. Preocupados com as perspectivas das literaturas de vários países de língua portuguesa, os africanos viam a Literatura Brasileira como aquela antiga colônia que se libertou e a perspectiva deles era uma pers- 
pectiva política. Começaram a editar com esses horizontes os autores dos vários países africanos de língua portuguesa.

Em Portugal, havia preocupação similar após a Revolução dos Cravos. A Caminho Editorial, como exemplo, editou uma bela edição da obra de Graciliano Ramos e na época eu comentei com o editor Zeferino Coelho que nem no Brasil havia uma edição tão cuidadosa como aquela. E ele me disse: devemos essa edição ao próprio Graciliano. Ou seja, era um momento de redescoberta da Literatura Brasileira, não apenas Graciliano, mas Jorge Amado e uma série de outros escritores passaram a ter grande penetração em Portugal. Mesmo anteriormente seus repertórios literários foram importantes, marcadamente para o neorrealismo português. Os grandes escritores portugueses davam grande importância ao Graciliano, principalmente o Carlos de Oliveira.

Comecei, então, a desenvolver essas ideias acerca da literatura sob uma perspectiva comparatista, a qual está presente desde minhas pesquisas iniciais até agora. Na minha livre-docência, a tese apresentada originou o livro "Literatura, História e Política", em que eu estabeleço uma relação entre os países de língua portuguesa. Meu destaque foi evidenciar a estratégia política de nos pensar em bloco. Do mesmo modo que existem os blocos econômicos, é preciso que haja os blocos culturais. Então, para nós que estamos acessando o mundo a partir do Brasil, é muito importante considerar o bloco dos países de língua portuguesa, mas também os da América Latina. Nesse caso, poderíamos pensar numa relação maior, que se estenderia à questão da nossa origem ibérica. Se observarmos nossa formação, a colonização da América Latina foi feita basicamente pela população do sul da ibéria, de modo que boa parte dos primeiros imigrantes veio dessa região, de uma região que é fundamentalmente mestiça, um ponto de encontro de Europa, África e Ásia. E havia muitos mouros, judeus e os próprios ibéricos mais antigos. Houve ali, portanto, uma mesclagem cultural que acabou marcando, também, a própria colonização futura da América Latina.

Nesse meu estágio de Mestrado em Portugal, eu queria saber qual era a presença de escravos em Lisboa em 1500, na época da descoberta do Brasil. Então eu comecei a ler textos de história e percebi num dos textos desse período dois parágrafos sobre a presença de escravos, um sobre a presença de judeus e apenas uma pequena referência aos mouros, com a afirmação de que "se confundiam com o conjunto da população lisboeta"... 
Luís Fernando Prado Telles: Mesmo em se considerando o critério da língua como unidade maior, o da nacionalidade parece não poder ser negligenciado diante dele, prova disso é o fato de que, na maioria das vezes, a comparação entre literaturas de uma mesma língua se estabelece com base no princípio de uma diferença, em geral estabelecida pela nacionalidade. Como o senhor pensa essa relação ambivalente nos Estudos Comparados de Literaturas em Língua Portuguesa, em que a língua funcionaria de modo a garantir a semelhança (e certa unidade) e a nacionalidade a diferença?

Benjamin Abdala Jr.: Nessa minha trajetória, eu acabei sendo um dos fundadores da Abralic, na segunda gestão, eu fui vice-presidente da Abralic. A primeira diretoria foi em Porto Alegre, com a Tânia Carvalhal; a segunda foi com a Eneida Maria de Souza, em Minas Gerais, da qual eu fui o vice; a terceira foi com o Silviano Santiago no Rio de Janeiro; e o quarto presidente fui eu e a Abralic veio para São Paulo. Eu era o presidente, e a professora Leyla Perrone-Moisés, a vice. Foi nesse momento que nós criamos a área de Estudos Comparados, em 1994. Criei a área, com apoio de professores da Literatura Portuguesa e Literatura Brasileira, embora eu já fizesse o comparatismo antes, a partir de dentro da área de Literatura Portuguesa.

Tínhamos, até então, uma tradição na USP das antigas cátedras. Seriam elas que deveriam dar origem aos programas de pós-graduação. Em universidades mais novas, há outros parâmetros, como é o caso da UFMG, em que se tem um único programa, que é o de Estudos Literários, que é enorme, mas dentro desse programa você tem áreas de concentração, como, por exemplo, Literatura Brasileira, Portuguesa, Teoria, etc. A organicidade se dá pelas linhas de pesquisas. Pode haver uma linha de pesquisa que organiza o estudo, por exemplo, tanto em Brasileira quanto em Portuguesa ou demais áreas de concentração. Trata-se de uma perspectiva que me parece muito boa. Inclusive eu cheguei a propor uma reorganização da pós-graduação aqui na USP, isso há 20 anos, que envolvia também a graduação. Na graduação achávamos que devíamos ter, no máximo, $50 \%$ de disciplinas obrigatórias e na pós os 16 programas de Letras deveriam ser reduzidos a quatro ou cinco. Na verdade, eu havia pensado em dois, mas considerava difícil essa aceitação: Estudos Literários e Estudos Linguísticos, aliás, como é na Unicamp. Por quê? As avaliações são feitas por meio de relatórios e com mais professores você consegue suprir certas deficiências e equilibrar mais 
os resultados. Essa era uma forma de conhecimento que eu tive quando eu estive na coordenação da área de pós-graduação e também pela minha experiência, durante seis anos, como coordenador da área de Letras na Capes e membro do CTC-ES dessa agência do MEC, além de ter sido, em duas gestões, representante de área no CNPq. Tive muito contato com o que ocorria em outras áreas e eu percebi que a nossa área de Letras ainda estava ligada àquela antiga ideia de cátedra.

Achei conveniente formar essa área de Estudos Comparados. Para tanto, tive apoio, inclusive, de professores da Literatura Portuguesa, tais como a própria professora Maria Helena Nery Garcez, que acabaram se dividindo, ficando nas duas áreas. Também tive apoio do pessoal da área de Brasileira, tais como o João Adolfo Hansen, o Flávio Aguiar, o Roberto Brandão e outros, que também participavam da nossa área, como António Dimas. Além disso, houve professores de língua, que trabalhavam com literatura, tais como a professora Elza Miné, por exemplo. Houve, também, a colaboração de professores de outras instituições. Agora, a perspectiva do comparatismo é uma perspectiva bastante ampla. Antigamente, então, você tinha aquele comparatismo que se fazia entre línguas diferentes. Hoje nós fazemos comparatismo não apenas com literatura de mesma língua, mas, inclusive, entre obras de mesmo autor. Ou mesmo entre literatura e outras linguagens, ou entre discursos, o discurso literário, o filosófico ou o político. Tenho defendido um comparatismo prospectivo: comparar para aprender com a diferença. Quem compara deve ser sujeito, nesse processo, como também o "outro", seja ele hegemônico ou um povo ágrafo. Esse "outro" possui uma experiência que nós não tivemos e precisamos criticamente aprender com ela. Após o nosso início nos estudos comparados, tivemos a satisfação de verificar que, em outras instituições, os estudos literários já começavam a se inclinar na mesma direção, a do comparatismo. É fundamental o conhecimento de nosso lócus enunciativo, de onde acessamos o mundo. Não posso analisar, por exemplo, a obra de Augusto Abelaira como se eu fosse um português, porque eu não sou português. Tenho de levar em consideração que o escritor é português, mas não há como pensá-lo apenas a partir do ponto de vista português. Devo ter a consciência que a nossa situação de brasileiro pode nos permitir ver o que um crítico português teria dificuldade de perceber. Logo, a afirmação crítica da diferença. $O$ fato de eu não ser português me faz ver coisas que um português 
não veria na obra de um português. Agora, do ponto de vista político, me parece importantíssimo pensar o mundo de língua portuguesa em bloco.

Do mesmo modo que temos a CPLP, que fica muitas vezes restrita ao plano simplesmente burocrático ou retórico, e fica mais no plano de pequenos acordos, você tem de pensar em uma política cultural mais ampla. É preciso que a nossa comunidade seja pensada não apenas do ponto de vista econômico, mas principalmente do ponto de vista cultural. Por exemplo, quando eu estava na coordenação da cooperação internacional aqui da USP (eu era vice-presidente), desenvolvi com uma professora do Mackenzie, e participação da PUC-SP, um projeto de sensibilização do jovem timorense para a língua portuguesa por meio da canção popular brasileira. Para esse projeto, eu consegui apoio do Itamaraty, patrocínio da Infraero e do Exército Brasileiro que estava lá. Mandamos vinte alunos da USP, Mackenzie e PUC-SP para lá. Esses alunos deram pequenos cursos para os alunos timorenses. Foi um sucesso! Trata-se de um movimento de integração.

A perspectiva dos Estudos Comparados me parece importante do ponto de vista político e do ponto de vista do conhecimento. Principalmente a partir da minha experiência de seis anos da CAPES, percebi que essa perspectiva diz respeito à ideia de que todo conhecimento novo é multi/interdisciplinar. Se você permanecer na barreira disciplinar, você ritualiza aquilo que já é conhecido. Se você quiser buscar um conhecimento novo você tem de romper a barreira disciplinar. Isso é imprescindível, isso existe em todas as áreas, não deve ser pensado apenas na literatura.

A questão da nacionalidade é importante. $O$ critério do nacional existe, mas não pode ser o único, não pode ser uma barreira. Então, por exemplo, se eu trato da questão da literatura de autoria negra, africana, eu posso estabelecer pontes, como muitos alunos meus fizeram em estudos de pós-graduação, com a literatura de autoria negra de outros países, inclusive dos Estados Unidos. Ou mesmo a comparação entre as próprias diferentes literaturas africanas, em que a questão da nacionalidade deve ser considerada, ou ainda dentro de um único país, em que há diversas línguas, como, por exemplo, um país como Angola, que tem 11 línguas principais, afora o português. O português é hoje, nesse país, a primeira língua, a mais falada. É a primeira língua de mais da metade da população de Luanda, a qual tem $60 \%$ da população de Angola. Nesse país, a língua portuguesa tem o papel político importante de promover maior coesão nacional. 
Luís Fernando Prado Telles: Conforme pude verificar nos documentos dos arquivos de processos do Departamento, o pedido de credenciamento da área de Estudos Comparados de Literaturas em Língua Portuguesa foi aprovado pelo Conselho de Departamento, em parecer assinado pelo professor Alfredo Bosi, em 04 de março de 1993; em 27/04/1993 foi aprovado pela CPG em parecer assinado pelo professor Francis Henrik Aubert e, na sequência, se deu a aprovação pela Câmara de Avaliação, em 14 de outubro de 1993. A Câmara Curricular, em sessão de 18 de outubro de 1993, aprovou a criação da área, mas o Pró-Reitor de Pós-Graduação, à época, o professor Moacyr Mestriner, perguntava se a área não se sobrepunha a algumas áreas já existentes na Unidade: Literatura Portuguesa e Literatura Brasileira. Em 17 de novembro de 1993, a professora Maria Aparecida Santilli responde, do seguinte modo: "A área proposta não se sobrepõe a outras. Destina-se a desenvolver outro trabalho, específico $e$ articulado entre as disciplinas dela constantes, para chegar a um resultado diferente daquele que resulta da pesquisa feita em cada área isoladamente, como seja na de Literatura Brasileira e Literatura Portuguesa. Por outras palavras, o objeto de trabalho da área ora proposta vincula-se, enquanto princípio e consequência, aos estudos comparatistas como também revelaram o Parecer da Comissão de Pós-Graduação da Faculdade de Filosofia, Letras e Ciências Humanas e o Parecer de Assessor". Tendo em vista que a área marca este diferencial em seu estabelecimento institucional e tendo em vista a sua já longa história, seria possivel traçar, em linhas gerais, o seu processo de criação, seus momentos decisivos na história da Instituição, bem como indicar os principais resultados e contribuições?

Benjamin Abdala Jr.: Essa perspectiva acabou contaminando outras áreas. A área de Literatura Portuguesa em si só existe aqui na USP, enquanto área separada. Até nós tivemos possibilidade de fundir a área de Estudos Comparados com a de Literatura Portuguesa. Tentei, mas houve resistência. Poderíamos ter criado uma grande área, talvez, de Estudos de Literaturas de Língua Portuguesa, em que teríamos áreas de concentração, uma área de Portuguesa, outra de Comparadas e outra de Africanas. E costurando isso tudo, justamente as linhas de pesquisa, que dariam organicidade às diferentes áreas dentro dessa grande 
área. Por exemplo, uma linha de pesquisa que está bem divulgada, por exemplo, como literatura e vida social (até vou fazer uma palestra sobre isso), esse tema, ou linha, poderia amarrar as áreas. Inclusive, aqui na USP, o pessoal está voltando a pensar numa reformulação dos programas de pós-graduação no sentido de colocar as áreas de concentração trabalhando numa mesma linha de pesquisa.

Luís Fernando Prado Telles: A partir da década de noventa, o Centro de Estudos Portugueses passou a abrigar estudos não apenas de Literatura Portuguesa, mas também os Estudos Comparados em Literaturas em Língua Portuguesa, prova disso são os conteúdos presentes nos três números das revistas do referido centro publicas entre os anos de 1998 e 2000. O senhor poderia discorrer um pouco sobre a história desse Centro de Estudos e de suas publicações?

Benjamin Abdala Jr.: Havia inicialmente o Instituto de Literatura Portuguesa. Esse Instituto, no início, tinha um estatuto parecido com o do IEB (Instituto de Estudos Brasileiros), e era dirigido pelo António Soares Amora. Tinha um prédio lindo e tal, no centro de São Paulo, e tinha apoio de entidades portuguesas. Quando houve a mudança da faculdade para o campus universitário, o instituto acabou sendo extinto e foi rebaixado à condição de centro. Nesse momento, inclusive, a biblioteca do centro foi alocada na biblioteca da Faculdade de Letras e, posteriormente, foi distribuída na biblioteca da $\mathrm{FFLCH}$, indistintamente. Bom, mas a história do Centro foi a seguinte. A direção do centro sempre foi designada pela congregação, apareciam os candidatos e a congregação votava, mas acontece que sempre eram as mesmas pessoas que permaneciam como diretoras do centro. Aí a congregação solicitou a relação dos membros do Centro. A pessoa que mandou a relação colocou em letras maiúsculas uma porção de nomes e em letras minúsculas alguns outros nomes, seguidos da observação de que estes não eram muito participantes do centro. Bem, isso criou um caso na congregação e foi aí que eu propus como candidato para o diretor do Centro o nome da professora Maria Aparecida Santilli. Nesse momento, já havia sido criada a área de Estudos Comparados. Bem, aí a professora Santilli acabou vencendo a eleição, com noventa por cento dos votos, para assumir a direção do CEP. Enfim, aí mudou tudo. Inclusive, nesta sala em que estamos, há todo o 
acervo da professora Santilli, que foi mandado para cá pelos filhos dela, depois que ela faleceu.

Foi depois dessa reviravolta, na segunda metade da década de noventa, que houve a iniciativa de organização desses números da revista, os quais, inclusive, fui eu que dirigi. Bem, mas depois, houve a necessidade, foi solicitado isso pela USP, de os centros adequarem seus estatutos ao modelo único da Universidade. Foi então que resolvemos mudar o nome para Centro de Estudos das Literaturas e Culturas de Língua Portuguesa, que contemplaria também a Literatura Portuguesa. A intenção inicial era que a existência do Centro facilitasse o intercâmbio com outras instituições. No início, conseguimos isso. Por exemplo, o próprio Instituto Camões foi um importante parceiro, ajudou-nos a criar a Revista Via Atlântica. Eu acredito que o atual centro, inclusive, para sobreviver, é preciso que continue buscando recursos externos ao âmbito da Universidade. A minha intenção sempre foi que houvesse a participação de pesquisadores de outras áreas, inclusive de outros cursos, como o de história. Por exemplo, porque um pesquisador da história que desenvolve pesquisas sobre Portugal ou sobre a África não poderia se servir do Centro? Há o convite aberto à comunidade em geral. Bem, quanto à Revista do Centro de Estudos Portugueses, ela se encerrou justamente com esses três números anteriormente referidos.

Luís Fernando Prado Telles: De que maneira a criação da área influenciou, na Instituição, o estudo da Literatura Portuguesa? Como se estabelece o diálogo destas áreas?

Benjamin Abdala Jr.: Num primeiro momento, eu fiquei na Portuguesa e na área de Estudos Comparados, mas com o tempo eu fui deixando a Portuguesa e me dedicando apenas aos estudos comparados. No início, houve uma certa interação e com a entrada de professores novos na Literatura Portuguesa isso foi se acentuando, visto que muitos deles tinham já essa perspectiva comparatista. Muitos outros, também, lecionam essa disciplina na graduação, mas na pós-graduação atuam na área de Estudos Comparados. Mas essa relação entre áreas tem toda uma história dentro da política interna do Departamento que não vale a pena entrarmos.

O último curso que eu ministrei aqui sobre Literatura Portuguesa foi sobre o simbolismo português, o catedrático da época, ou melhor, o professor titular, 
pois na época já não existia mais cátedra, fazia reuniões em que dizia que autores deveriam ser dados no curso e em reuniões deliberava-se sobre quais e quais poemas deveriam ser trabalhados em aula. Então, você tinha de seguir aquelas receitas. Enfim, havia uma turma de alunos para cursar a disciplina num determinado ano e que era dividida com colegas escalados para ministrá-la. Dividi esse curso com mais três colegas. No dia do início das aulas, eu cheguei à sala de aula e falei: o curso é sobre o simbolismo, vamos estudar os autores que precisamos estudar, mas eu quero fazer algumas pontes com a literatura brasileira, com a literatura francesa e a música (Débussy). Logo, eu já estruturei o curso, portanto, a partir de uma perspectiva comparatista. O resultado foi que eu acabei ficando com noventa por cento dos alunos, ao passo que os outros professores com o restante da turma. Essa experiência foi contundente para que eu deixasse de dar as disciplinas de Literatura Portuguesa na graduação, embora continuasse por um tempo atuando na área de Portuguesa na Pós-Graduação.

Luís Fernando Prado Telles: Qual a principal forma de divulgação, atualmente, das pesquisas dos Estudos Comparados de Literaturas de Língua Portuguesa. Qual é o estado da arte das pesquisas nessa área e quais as suas perspectivas futuras?

Benjamin Abdala Jr.: Hoje, a principal forma de divulgação é mesmo a Revista Via Atlântica, que é editada totalmente online. Agora, do ponto de vista da pesquisa científica, o conhecimento novo vem vindo mesmo da área de Estudos Comparados. Eu participo, inclusive com cargos na diretoria, da Associação Internacional de Lusitanistas desde sua formação. Fui editor da revista da AIL durante alguns anos. Inclusive, a AlL vai realizar o congresso dela agora em Cabo $V_{\text {Verde }}^{5}$. Na Associação, essa visão mais comunitária dos Estudos Comparados é predominante. Nesse ano, inclusive, conseguimos colocar o congresso na África. Trata-se de uma Associação que abarca não apenas a literatura, mas também trabalhos sobre língua e cultura. Enfim, no momento de minhas pesquisas atuais tenho sempre apontado para essa direção do pensamento comunitário. Não se trata de diminuir a Literatura Portuguesa, acontece que do ponto de vista políti-

5 O XI Congresso da Associação Internacional de Lusitanistas ocorreu em Mindelo, Cabo Verde, entre os dias 21 e 25 de julho de 2014. 
co, pensar em bloco é muito mais forte e produtivo. É muito melhor unir forças do que segmentá-las. A perspectiva, penso eu, deve ser a de inserção da língua e da literatura portuguesa no mundo e para Portugal isso é muito importante. No início dessa discussão toda sobre o acordo ortográfico, certa vez, estava conversando com o escritor português Miguel Alçada Batista e lá em Portugal estavam criticando muito o acordo, dizendo que isso era coisa de brasileiro e que não havia a necessidade e tal. Bem, eu me lembro de que estava conversando com ele, e ele me disse algo mais ou menos assim: "Ainda bem que o Brasil resolveu fazer esse acordo, se não ele próprio iria propor as mudanças, com seus duzentos milhões de habitantes, e nós iríamos ter de ir atrás"...

Reafirmo, então, que eu considero que nossa perspectiva de ensino e pesquisa tem mesmo de se pautar na ideia de comunidade. Recentemente, eu apresentei um texto sobre literatura e reflexões comunitárias no último congresso da Abraplip, que ocorreu em Campo Grande. Bem, era um congresso de Literatura Portuguesa em que eles me pediram para falar sobre o comparatismo. Nesse texto, há uma espécie de síntese do que eu penso atualmente a respeito dos estudos sobre literatura ${ }^{6}$.

6 O texto aqui mencionado foi proferido em conferência do dia 25/10/2013, no XXIV congresso da Abraplip, ocorrido entre os dias 20 e 25 de outubro de 2013, em Campo Grande, tendo sido promovido pela Universidade Federal do Mato Grosso do Sul. O texto citado pelo professor Benjamin Abdala Jr. intitula-se: "A literatura, a política e o comunitarismo supranacional". 